\title{
Practice perspectives on learning analytics in higher education.
}

\begin{abstract}
Learning analytics have taken higher education by the proverbial "storm". Universities primarily employ learning analytics at the level of metrics to satisfy institutional requirements, but are also investing significant effort in technical development. In the domain of teaching, learning analytics are making an appearance but are much less developed than in institutional or technical domains. On the basis of the potential of learning analytics to inform teaching practice and thus improve learning experiences, course instructors are now encouraged to use learning analytics at classroom level. Early forages are giving mixed results, and some confusion reigns among teaching staff in relation to the usability/value of learning analytics. The fundamental premise of the present chapter is that if potential of learning analytics to improve learning experiences is to be realized, then learning analytics must shift further into the practice domain, and this requires the projection of learning theory onto learning analytics.
\end{abstract}

\section{Key terms}

Learning analytics, higher education, Deming cycle, constructivism, social constructivism, connectivism, learning theory

\section{Introduction}

Enter the search term "learning analytics" in Google and in around a half second it will return something over 1.3 million results with the majority of results referring directly to higher education. The density of completely relevant results drops off at the tail end of the results but the large volume of relevant results is still quite impressive. Learning analytics has definitely taken higher education by the proverbial "storm". The excitement surrounding the potential of learning analytics is palpable across institutions of higher education, and though learning analytics systems are still nascent, institutions are already investing significantly in their development and implementation.

Why the excitement surrounding learning analytics? The backstory reads along these lines: higher education institutions continue to be placed under stress as the forces of competiveness and difficult economic times bear down. The need to attract and retain students is of utmost strategic importance. In effort to survive and thrive, institutions turned to information and communication technology (ICT) for delivery of educational experiences, as a means for attracting and retaining more students. ICT satisfies the expectations of the millennial generation, provides the flexibility of access to education, attracts greater numbers from diverse geographical locations, and is seen to provide some pedagogical benefits to further improve the learner experience. A side effect of interaction with digital systems is the precipitation of great volumes of data. Data resulting from student interactions with various university information systems (including learning management systems) is considered useful intelligence about students. In particular, data generated by students as they engage in study and learning activities can provide insights into the learning approaches and processes of students, and such insights potentially provide a basis for delivering 
improved quality of education and experiences. With the overarching goal of gaining competitive advantage through student attraction, success and retention, institutions are making significant investment in learning analytics both in developing and implementing systems, and in researching how learning analytics can be utilized to meet the strategic goals of the university. From the top administrative echelons down to the teaching faculty, the use of learning analytics is strongly encouraged. Thus, the phenomenon of learning analytics in higher education arises largely from the convergence of institutional needs with technological capabilities.

If the history of analytics in marketing and business is anything to go by, learning analytics likely do hold considerable potential for positive impact on higher education. Much of what universities do with learning analytics have to do with fulfilling the needs of formal reports and credentialing, focusing primarily on the big picture with regards to attracting and retaining students, graduate success, planning and institutional accountability (Wilson, Watson, Thompson, Drew, \& Doyle, 2017). In comparison the use of learning analytics for institutional purposes, the application of learning analytics to teaching has been slower in eventuating, and related literature is comparatively sparse. But, from the viewpoint of students, the core service provided by universities is provision of quality learning experiences, and hence interfacing learning analytics directly with learning and teaching activities is crucial and should attract considerably more research attention than it has currently received. In the emerging literature the potential for positive impact of learning analytics on both higher education institutions and student learning is not strongly disputed but some early results are giving mixed findings and casting doubt over the value/usability of learning analytics in learning. Learning analytics systems do certainly do yield volumes of data about learners and their activities. If generated data can be used effectively to help understand learners and their needs, then learning analytics at classroom level must hold some potential for improving the quality of learning experiences. However, it is yet very early days in learning analytics and learning is extremely complex so there is much to be done in realizing the potential of learning analytics for improving the quality of learning experiences.

If the preceding experience with learning technologies is anything to go by, then it is not surprising that early forages into learning analytics are characterized by a techno-centric perspective. The sophistication of the technology underlying analytics systems is such that learning analytics is quite firmly embedded in the IT domain and is being driven predominantly by IT departments and technology enthusiasts (Wilson, Watson, Thompson, Drew, \& Doyle, 2017). In keeping with the technological basis for learning analytics, there is a great deal of emphasis on learning analytics in the data sciences. Much effort is being expended to develop better learning analytics systems, and a technical focus on the analysis of big data. Some are looking towards learning analytics systems that can gather a wider array of data and provide effective visualization; others are looking toward predictive models of student achievement and the modelling of learner behaviour.

While development of the capabilities of learning analytics related technologies is obviously necessary, it is not sufficient if learning analytics are to make positive 
impact in learning. Undeniably, the field of learning analytics is very complex and necessarily multi-disciplinary, and since the field of learning analytics has been made possible by technology, a technical perspective tends to prevail. Furthermore, learning analytics are historically connected with social and political agendas having to do with completion rates, student engagement and success, and are designed to serve the needs of the institution rather than the learners (Kitto, Lupton, Davis, \& Waters, 2017; Corrin, Kennedy, \& Mulder, 2013). Hence, when it comes to learning analytics in the domain of learning and teaching, the upshot of the latter two factors is that learning analytics thus far are politically and technologically embedded, and very little in terms of frameworks to do with learning have been integrated with the field of learning analytics.

With respect to the potential of learning analytics to positively impact on learning and teaching practices, existing research gives mixed results. For example the accuracy of predictive student models is not consistent across contexts, some predictive models identify predictors irrelevant to teaching practice and the use of dashboards, intended to help students, are proving to do the opposite (Gašević, Kovanović , \& Joks, 2017). In agreement with Gašević, Kovanović and Joks (2017) the mixed results from studies on the impact and/or effectiveness of learning analytics on learning and teaching are, at least in part, due to a lack of grounding of learning analytics in the theory and practice of learning and teaching.

The thesis underlying this chapter is that if learning analytics is to make grass roots impact on learning and teaching then discussion must shift somewhat away from institutional metrics and techno-centric discussion towards the domain of teaching practice at classroom level. Recognizing the potential of learning analytics in teaching practice requires the use of theories and knowledge of learning as analytical frameworks. In literature, it is beginning to be acknowledged that there exists a need to shift discussion of learning analytics from the dominating technical perspective to more balanced discussion incorporating practice based perspectives is only beginning to recognized (Stewart, 2017; Gašević, Kovanović , \& Joks, 2017; Gašević, Dawson, Rogers, \& Gasevic , 2016). Hence, in the present chapter, a practice perspective is adopted, for the purpose of making a contribution to shifting learning analytics further within the domain of learning and teaching practice. When learning analytics is discussed from the perspective of learning and teaching theories, guiding questions are raised and processes begin to materialize as to how data and information yielded by learning analytics might be conceptualized in a way that enables learning analytics to become a useful tool for better understanding the richness of learners and their learning, and therefore become a more useful tool for informing learning and teaching practices.

Pivotal to the ensuing discussion is a definition of the term "learning analytics" and clear statement of the purpose of learning analytics. Hence, our discussion of moving learning analytics to the practice domain begins with the definition and explanation of purpose of learning analytics. The Deming cycle and the data to wisdom hierarchy are then used to frame the process of achieving the purpose of data analytics. The need for a base of learning theory is established and the theories of constructivism, socio-constructivism and connectivism are discussed 
with respect to their value in bringing learning analytics into the domain of learning and teaching practice.

\section{Definition and purpose of learning analytics}

According to the first International Conference on Learning Analytics (cited in (Long \& Siemans, 2011, p. 40)

"Learning analytics is the measurement, collection, analysis and reporting of data about learners and their contexts, for purposes of understanding and optimising learning and the environments in which it occurs"

The above definition is commonly used through literature, and is adopted for the purposes of the present chapter. There are many variations on the definition of learning analytics but most definitions capture three elements of the learning analytics concept: the collection of data, searching for patterns or trends in data, and the purpose of understanding. The definition from the First International Conference on Learning Analytics is adopted for the purposes of the present chapter because in addition to the elements of data collection, analysis and understanding it also captures another essential element of learning analytics understanding for the purpose of optimizing or improving the environment in which the data occurs. For the various stakeholders of learning analytics (students, teaching staff, administrators, policy makers) the value of learning analytics is ultimately in seeking improvement of some aspect of the learning and teaching context of the institution. To be truly useful for learning and teaching, learning analytics must offer insights into learning processes and be able to be "theoretically interpreted" (Gasevic, Dawson \& Siemans, 2015 cited in van den Bogaard \& de Vries , 2017).

\section{Framing learning analytics in practice}

Given the driving purpose of learning analytics is to bring about improvement in the quality of university environment as experienced by it's 'clients' - the learners, it is useful to bring the Deming cycle to bear on the field of learning analytics. The Deming cycle (Figure 1.0) was developed originally as a framework for the improvement of the 'organisation' and is widely adopted for continual improvement practice frameworks across organizational and management literature. 


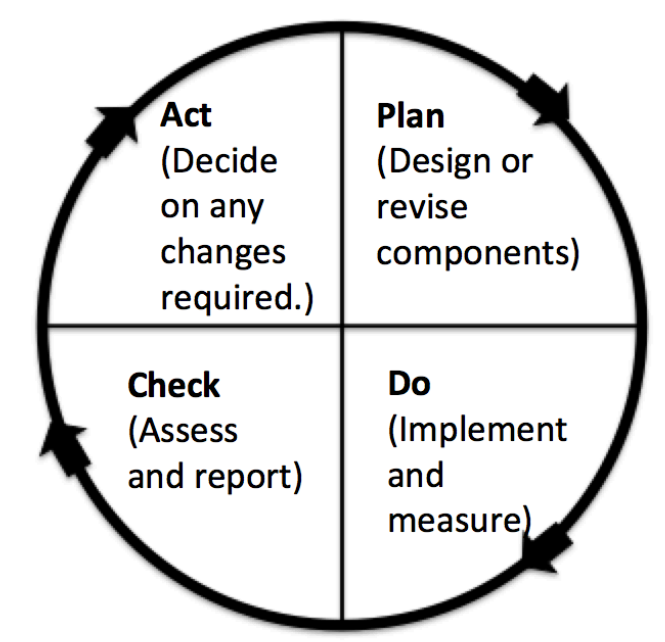

Figure 1 The Deming Cycle for continuous improvement

As shown in Figure 1.0, the Deming cycle consists of four iterative, continuously cycling steps aimed at facilitating evidence-based changes within an organisation. From the viewpoint of the Deming cycle, learning analytics, as data collection, measurement and analysis, is seen to serve the important purpose of informing changes to improve quality of practice, and hence the field of learning analytics shifts further towards a practice (rather than technical) perspective. Conceptualizing how learning analytics can be integrated to improve the quality of practice is aided by a consideration of the Data to Wisdom hierarchy (DIKW) (Ackoff, 1989). According to the DIKW framework, data is the result of observation and consists of objective facts, and numbers. Data taken on its own has no meaning (Baldassarre, 2016). Put in context, data produces information. Information is merely organised and structured data in a way that is useful to visualize the data. Knowledge arises when information is related to the experiences, values, insights and competencies of an expert person. Knowledge is contextually synthesised learning (Baldassarre, 2016). If information and knowledge is assimilated into individual experiences (and may transform individual experiences), then wisdom arises. It is wisdom that enables decisionmaking and results in evidence-based changes to practice. Wisdom is understanding and is actionable (Baldassarre, 2016).

When in addition to the Deming cycle, the data to wisdom hierarchy (DIKW) (Ackoff, 1989) is now also brought to bear on learning analytics (figure 2.0). A framework to guide the process of integrating data analytics with practice to create evidence-based, positive changes emerges. 


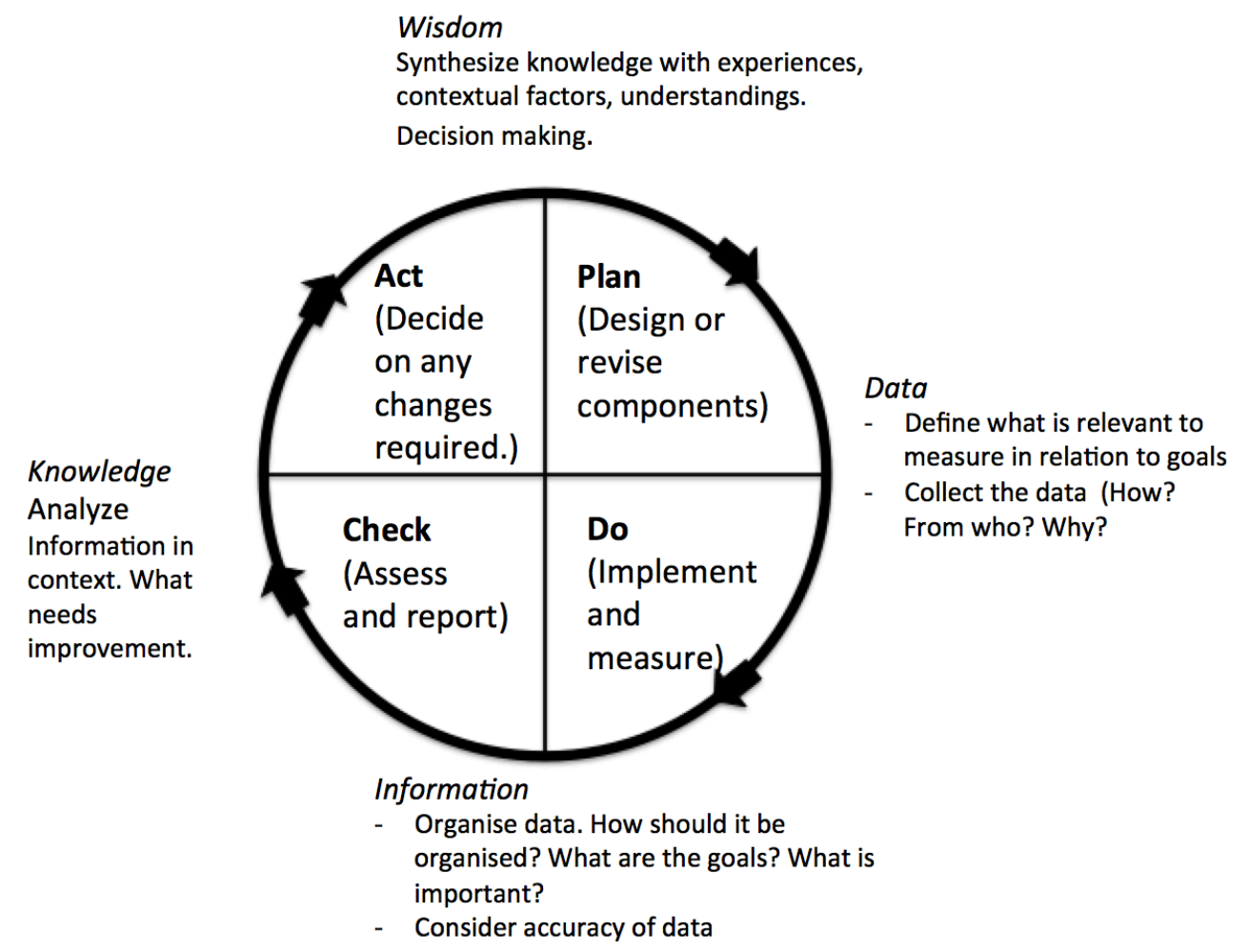

Figure 2 Moving towards a practice perspective on learning analytics with the integration of the Deming cycle with DIKW.

The framework in figure 2.0 lends some much-needed focus to the generation of information more relevant to learning and teaching, from learning analytics systems. Since learning analytics is primarily being used for the purposes of "credentialing or meeting reporting requirements" rather than for the purposes of informing learning and teaching (Corrin, Kennedy, \& Mulder, 2013, p. 201), teaching staff often experience confusion and scepticism around learning analytics. Many finding information reported by learning analytics to be "not particularly useful" (Corrin, Kennedy, \& Mulder, 2013, p. 203). The conceptual framework in figure 2.0 can help both system designers and teaching staff to focus in (or request access to) information and data that is targeted towards specific learning and teaching goals. DIKW, together with the Deming cycle place emphasis on identifying data and information that is relevant to the context, and also guides the process of moving from data to decision making required to enhance teaching practice.

The framework in figure 2.0 supports the process of improving the quality of learning experiences, and the process of moving from data through to the wisdom state required for decision-making and action. It also makes some inroads to positioning learning analytics away from the techno-centric perspective and closer to the domain of learning and teaching practice. However, the framework provides little guidance on establishing goals for improvement, selecting relevant data, and guiding teachers' sense making of generated data - these things require a theoretical frame. If the purpose of applying learning analytics to teaching and learning is to ultimately offer practical and theoretical insights into the learning process, then grounding learning analytics in learning theory is imperative - after all how can data be effectively organised, analysed, understood and synthesized 
with other knowledge and experiences if the phenomena to which it pertains is not understood and involved in the activity? Thus, it is argued that the frame of learning theory is required to guide data selection, collection and analysis within learning analytics. Learning theory facilitates the process of moving from data to wisdom in a manner that increases the practical value of learning analytics for improving learning and teaching practice. The following discussion intersects learning theory with learning analytics. The focus is on three key learning theories: constructivism, socio-constructivism and connectivism.

\section{Learning analytics framed by learning theory}

Much of the data generated in learning analytics is incidental to learners using a learning management system or engaging in other online learning environments. Data and information generated by learning management systems may, for example, show how many students have accessed a particular tool such as a Wiki, how long individual students have spent watching recorded lectures or spent in a particular activity, or how many times a particular student has visited the course assessment links. The data logs may be linked to goals such as engagement. Frequently, practitioner reports of usefulness or implementations of learning analytics report on variables such as logins and time spent online, and then proceed to draw conclusions about these variables as indicators of constructs such as engagement or academic performance. As Gasevic, Dawson, and Siemens (2015) observe, reporting on such variables in a way that is disconnected from the learning and teaching context ignores learner agency and the influence of the design of the instructional learning environment on learner actions. Educational research suggests that the instructional environment (and the learning and teaching theories it embodies) significantly influence how the learner interacts with the learning environment (Gasevic, Dawson, \& Siemens, 2015).

The notion of learner agency is fundamental to constructivist views of learning. Much of the existing research in learning analytics in classrooms does not acknowledge the self-direction of learners and this is indicative of the urgent need to integrate learning analytics with learning and teaching theory and principles. Constructivist learning theory has an established history of being applied to the design of technology based instructional environments. It is also a useful framing for understanding learner interaction with learning environments, and thus also a useful underpinning for learning analytics in the domain of learning and teaching. According to constructivist learning theory, the learner is an active participant in their own learning, and will choose their own pathways, constructing their own understandings. The teacher as facilitator provides conditions that encourage the learner to make connections with existing knowledge, in the process either extending their existing understanding (schema) or changing their existing understanding. From the constructivist perspective, learners will interpret, interact and learn in their own individual ways. With respect to learning analytics, the frame of constructivism draws attention to the individual differences between learners. The type of data that is relevant to gain includes individual student characteristics such as learning styles, and prior knowledge and demographic profiles. Learners as active agents in their own construction of learning will approach learning differently, taking different pathways, preferring those activities that align more with their own needs and 
their learning styles. Hence, relevant data might include the various pathways taken by different learners. The interpretation of that data though will include making relationships with data pertinent to relevant students' individual characteristics. Similarly, the interpretation of other data and information gained through learning analytics will not be short-sighted and jump to conclusions, but rather constructivism encourages evaluating information by taking into account how the individual learning styles may have interacted or responded to various elements of the learning environment. Practitioner researchers might look towards establishing relationships between what is happening 'online' with other events occurring in the course or even program or institution. Furthermore, constructivism can help explain the apparent variation in results of learning analytics research across different contexts.

Constructivist theory places attention on the power of the individual learner to make their own decisions about how they engage with the learning environment. While it is crucial to consider the individual learner, it is equally important to situate the learner within the social context of the learning environment. Socioconstructivist learning theory is thus applicable. Socio-constructivist theory extends the concept of the individual construction of knowledge, to knowledge construction as a social activity. From the perspective of socio-constructivist theory the learning activity is influenced by interaction with the teacher and with others in the learning situation. Learners construct their own knowledge through a process of discussion and knowledge negotiation with others (peers and teachers). Socio-constructivist theory, like constructivist theory, draws attention to the design of the learning environment but specifically to the social interactions that happen within it, and the role those interactions play in the individuals' construction of knowledge. The Zone of Proximal Development (what the learner can do on their own compared with what the learner can do with support) focuses on the influence of social interaction on learning. Socio-constructivist perspectives on learning analytics will encourage the reporting of data related to extent and nature of social interaction of learners and how that might be contributing (or not) to learner engagement and outcomes. Taking the socioconstructivist viewpoint leads to some useful interpretations and understanding of information generated by learning analytics. For example, on the foundation of socio-constructivism, it is known that the number of postings to a forum alone will not be sufficient to draw conclusions about student engagement. The word length of the contribution might also be recorded but to truly gain insight into learner engagement, data about who they have responded to and possibly the types and density of themes will also be useful. Other data such as the distance from instructor intervention or prompts is also potentially useful for interpreting data. Furthermore, according to socio-constructivist theory, social interaction is useful for reflecting on and refining (or creating) mental models. From this perspective, important data to capture through learning analytics might relate to theme analysis, theme density, interactions frequency over time to gain insight into the extent, and direction of, learners' evolution of understanding.

Thus far, constructivism in the realm of learning analytics brings the individuality of the learner to the collection and understanding of information. Socioconstructivism expands the understanding of information generated by learning 
analytics to include the social interactions and the process of social negotiation of knowledge. More recently, and strongly linked with learning in the 'connected' digital age is connectivism. Arising from the work of Siemans (2005)vconnectivism offers a 'networked' view of learning in which learning occurs through both interaction with others and through interaction with technology. Connectivism has been subject of criticism (perhaps more so than other established theories) with some questioning whether or not is indeed a new theory at all, or arguing that is merely a rehash of existing socio-constructivst theories or even activity theory (Goldie, 2016). The principles underlying connectivism are useful within the context of the discussion in the present chapter in that it provides a holistic view of the learning and teaching environments commonly experienced in higher education. The holistic view provided by connectivism anchors analytics as a component of a complex network of interactions and is a preventative of the simplistic gathering and interpretation of data in learning environment.

Connectivism theory seeks to explain how learning occurs both through interaction with humans and interaction with technology. It therefore forces consideration of how technology is used in the learning environment to achieve learning goals. The principles underpinning connectivism include:

- learning as process of connecting nodes from various information sources, learning and knowledge resides in both human and appliances;

- the capacity to learn is more important than what is already known;

- maintaining and facilitating connections is critical to the continual learning

- ability to make connections is core,

- "decision making is learning in itself"

(Goldie, 2016, pp. 1064-1065)

According to connectivism, the characteristics of successful networks are diversity (a wide spectrum of points of view), participant autonomy, connectivity, and openness (other perspectives are able to enter the system (Downes, 2006, 2012; Goldie, 2016)).

When overlayed on learning analytics, connectivism captures extremely well the complexity of the learning phenomena, and enforces a view of information and data that precludes shallow interpretation and understanding. Each unit of information generated by learning analytics systems must be viewed as emanating from a single node or information source point, but that source point is part of an interacting network. Knowledge can only be gained by considering interacting nodes. As a guide for teacher sense-making of information from learning analytics systems, connectivism enforces that the design of the learning environment (both technical and human dimensions) must be considered.

In defining what data is important to access, the core principles of connectivism encourage collecting data related to the various nodes of information, and organising data in ways that give information not only about how the learner interacts with those nodes individually but also the pathways the learner has taken to travel and /or expand their network of learning- bearing in mind that such pathway data must be examined and interpreted within the context of the 
learning environment. Data related to the decision-making process learners follow in navigating their way through the learning environment, and in how they interact with various nodes becomes important within the frame of connectivism. From the standpoint of connectivism, the goal of implementing learning analytics may relate to gaining insights into which connections learners are making, how often they are making connections, why are they making those connections, and how are they using their learning connections. Metrics feeding into information about learner autonomy and the outcomes of that autonomy, the number of different perspectives that enter the systems, the opportunities for connection among nodes and the quality and outcomes of those connections, are all, from the connectivism perspective, possible definitions of data that is relevant and gives genuine insight into learning activity.

Constructivism, social constructivism and connectivism, as theories provide a framework for explaining and conceptualizing learning (albeit in slightly different ways). The three theories were selected for discussion as they are dominant in the field of quality learning and teaching in higher education, and constructivist/socio-constructivist approaches, in particular, form the cornerstone of much of the active learning pedagogies being promoted in higher education. These theories (like other learning theories) embody beliefs about the role of the learner, the role of the teacher and about how learning best occurs, and hence provide useful direction in the selection, organisation, interpretation and understanding of data in generated by learning analytics. The base of theory helps practitioners establish learning focused goals for using learning analytics, helps identify the elements of the learning environment that should be measured, and facilitates sense-making in learning analytics, and ultimately raises the likelihood of learning analytics being used to enhance the quality of learning and teaching.

\section{Conclusion}

Significant resources are being invested in learning analytics with most of the investment focusing on fulfilling institutional needs related to metrics for the purposes of credentials and policy, and on technical developments. Although there is some emerging emphasis on learning analytics within the domain of learning and teaching practice, it is crucial to institutions that further work in learning analytics takes place at the practical level of classrooms and teaching activity. The ultimate purpose of learning analytics in the classrooms of higher education settings is to improve the quality learning experiences for students. The quality of learning and teaching experienced by students is not the only factor impacting on students' overall experience of a university and it is not the only determinant of student attraction, retention; but students come to university to experience quality learning that will place them in good stead for careers, so good quality learning experiences are most certainly of critical importance to the survival of the institution, and it is why learning and teaching quality has become a key strategic focus across universities.

Learning analytics in most institutions are situated in the technical areas. Rising from sophisticated and emerging technologies, learning analytics is most prominent in the technical domain and is attracting much interest in data science 
and related technical fields. There is an unfortunate, but understandable, trend towards a very techno-centric view of learning analytics. The techno-centric view does little to help realize the purpose of analytics, which is to understand and subsequently make improvements to the environment within which the data occurs i.e. the learning environment. With respect to learning and teaching in higher education, there exists quite a distance between learning analytics and the domain of practice. There is a need to shift learning analytics further into the domain of learning and teaching practice. In the present chapter, with the aim of stimulating thought and discussion on learning analytics in the practice domain, the Deming cycle has been brought to bear on the field of learning analytics as a tool for achieving improvement in the quality of the learning experience. The Deming cycle for continual improvement relies heavily on information used for decision-making. Thus, the data to wisdom hierarchy (DIKW) was overlayed onto learning analytics along with the Deming cycle. The DIKW framework makes abundantly clear that gaining true understanding from data is dependent on the integration of contextual factors as well as the understandings and experiences of the various stakeholders. Ultimately, if data and information is to be of any use it cannot be separated from an understanding of the ecosystem of interactions that generate it. It is at this point that necessity of framing learning analytics within learning theory becomes clear.

Learning theories, as theory do, provide some explanation of how learning occurs, and provide a basis for understanding the inter-relationships among the various elements and participants of the learning situation. In the present chapter, constructivism, socio-constructivism and connectivism were discussed in terms of each of the theories contributes to bringing learning analytics further into the domain of practice. It was argued that a base of theory assists with identifying goals for improvement of the learning experience, defining relevant data to be collected, organising data in a focused manner that is pertinent to the learning context and learning goals, and interpreting and making sense of the data in meaningful ways. Furthermore, as the DIKW hierarchy stipulates, decision making relies on wisdom, and wisdom is the synthesis of knowledge, contextual factors, and experiences - a base of learning theories can act as the driver for the required synthesis.

In fact, seeking to use learning analytics without a base of learning theories and knowledge is likely to be of little use (and perhaps even counter-productive). In the absence of a base of learning theory, learning analytics represents no more than a set of digital footprint, tends to lead to over-simplification of the learning phenomena and relegates learning to the relative simplicity of behaviourism, if not a tendency back towards purely instructivist approaches. The data collected by learning analytics systems must be reliable and truly indicative of learning rather than simply a loose collection of metrics that happen to be precipitating from learner's interactions with digital systems - the framing of learning analytics within learning theories is essential to gaining create genuine insights from learning analytics, and to form a basis of evidence-based changes to practice. 


\section{Bibliography}

Ackoff, R. L. (1989). From data to wisdom,. Journal of Applies Systems Analysis, 16, 3-9.

Baldassarre, M. (2016). Think big: learning contexts, algorithms and data science . REM - Research on Education and Media , 8 (2).

Corrin, L., Kennedy, G., \& Mulder, R. (2013). Enhancing learning analytics by understanding the needs of teachers . 30th ascilite Conference 2013 Proceedings (pp. 201-205). Macquarie University.

Gašević, D., Dawson, S., Rogers, T., \& Gasevic , D. (2016). Learning analytics should not promote one size fits all: The effects of instructional conditions in predicting academic success . Internet and Higher Education , 28, 68-84.

Gašević, D., Kovanović , V., \& Joks, S. (2017). Piecing the learning analytics puzzle: a consolidated model of a field of research and practice . Learning: Research and Practice , 3 (1), 63-78.

Gasevic , D., Dawson, S., \& Siemens, G. (2015). Let's not forget: Learning analytics are about learning. TechTrends , 59.

Goldie, S. (2016). Connectivism: A knowledge learning theory for the digital age? Medical Teacher , 38 (10), 1064-1069.

Kitto, K., Lupton, M., Davis, K., \& Waters, Z. (2017). Designing for student-facing learning analytics . Australasian Journal of Educational Technology , 33 (5), 152-168.

Long, P., \& Siemans, G. (2011). Penetrating the fog: Learning analytics learning and education. EDUCAUSE Review , 5, 30-32.

Siemens, G. (2005). Connectivism: a learning theory for the digital age. International Journal of Instructional Technology and Distance Learning , 2, 1-8.

Stewart, C. (2017). Learning Analytics: Shi ing from theory to practice. . Journal on Empowering Teaching Excellence ., 1 (1), 95-105.

Van den Bogaard , M., \& de Vries , P. (2017). "Learning Analytics is about Learning, not about Analytics." A reflection on the current state of affairs. 45th SEFI Conference, 18-21 September 2017, Azores, Portugal . Portugal .

Wilson, A., Watson, C., Thompson, T., Drew, V., \& Doyle, S. (2017). Learning analytics: challenges and limitations. Teaching in Higher Education , 22 (8), 991-1007.

\section{Key Terms}

\section{Connectivism}

A learning theory in which learning takes place through the process of connecting nodes from various information sources, learning and knowledge resides in both human and appliances.

\section{Constructivism}

A learning theory placing the individual at the centre of the learning experience. The learner is an active agent in the construction of their own knowledge. The teacher facilitates the knowledge construction process through the provision of opportunities.

\section{Deming cycle}


A framework for the improvement of the 'organisation' and is widely adopted for continual improvement practice frameworks across organizational and management literature.

\section{Data to wisdom hierarchy (DIKW)}

Data is simply numbers and meaningless. Information is merely organised and structured data in a way that is useful to visualize the data. Knowledge arises when information is related to the experiences, values, insights and competencies of an expert person. Knowledge is contextually synthesised learning (Baldassarre, 2016). If information and knowledge is assimilated into individual experiences (and may transform individual experiences), then wisdom arises. Decisionmaking occurs on the basis of wisdom.

\section{Learning analytics}

"Learning analytics is the measurement, collection, analysis and reporting of data about learners and their contexts, for purposes of understanding and optimising learning and the environments in which it occurs" (Long \& Siemans, 2011, p. 40)

\section{Socio-constructivism}

Like the theory of constructivism, socio-constructivism acknowledges the learner as active in the construction of their own knowledge. However, knowledge construction occurs primarily as a result of social interaction. Knowledge is constructed through a process of discussion and negotiation 